\title{
Acute hypercapnic respiratory failure as a rare complication of meningoencephalitis: Two case reports
}

\author{
Leonidas Grigorakos, Katerina Tzortzopoulou, Anastasia Alexopoulou, Eva Sotiriou, Dimitra Markopoulou, Athanasios \\ Moles, Alexandros Agathonikou, Charalambos Ladakis \\ Faculty of Nursing, National and Kapodistrian University of Athens, Greece
}

Received: January 2, 2017

Accepted: February 20, 2017

Online Published: March 13, 2017

DOI: $10.5430 /$ crim.v4n2p31

URL: https://doi.org/10.5430/crim.v4n2p31

\begin{abstract}
Background: Differentiated diagnosis of meningoencephalitis in elderly patients, when an uncommon picture of respiratory infection leading to acute hypercapnic respiratory failure (AHRF) and without neurological signs is present, may raise serious difficulties.

Case report: Two patients aged 72 (patient 1) and 75 (patient 2), without any medical history of respiratory problems, were hospitalized during spring with influenza symptoms. Within less than 24 hours from their admission, patients developed AHFR, which led to disturbances of arterial blood gases (ABGs). They were intubated and transferred, mechanically ventilated, to our intensive care unit (ICU). After normalization of ABGs, a weaning process followed. Weaning was unsuccessful, as unexpected neurological semiotics occurred. The imaging of neurological MRI revealed no special damage apart from microangiopathy. Further investigations through lumbar puncture with cerebrospinal fluid (CSF) testing revealed meningoencephalitis. Antiviral treatment was applied and the outcome was successful for both patients.

Conclusion: Critical care medical personnel should be aware of the event of viral meningoencephalitis in elderly patients with AHRF. Especially in the middle of influenza endemic periods, the management of elderly patients may not be appropriate, thus resulting in serious delays for a proper treatment of disease. Laboratory screening of blood and urine, as well as other body fluids, can help detect and determine brain infection. Results from these tests can help exclude other diseases that mimic meningoencephalitis. In cases of patients who are hospitalized in the ICU due to AHRF and do not exhibit neurological abnormalities from the onset of illness, lumbar puncture and check of CSF should be a routine examination. Prophylactic vaccination of high-risk groups may be of crucial importance for preventing complications in patients who develop meningoencephalitis. However, once infected with this disease, the positive outcome is highly dependent on the immediate diagnosis and proper treatment of patients in the ICU.
\end{abstract}

Key Words: Meningoencephalitis, Acute hypercapnic respiratory failure, Lumbar puncture, Cerebrospinal fluid, Herpes simplex 2, Cytomegalovirus meningitis

\section{INTRODUCTION}

Since 1950, antibiotics played a crucial role in the decrease of mortality rate due to infectious diseases. Nevertheless, it still represents a serious problem in the case of elderly age groups, who remain more vulnerable to health problems. This is so because elderly population is more frequently affected by chronic diseases (cardiac failures, diabetes mellitus or hypertension) which, at their turn, reduce the immunolog-

\footnotetext{
* Correspondence: Leonidas Grigorakos; Email: grigorakos@ parliament.gr; Address: Faculty of Nursing, National and Kapodistrian University of Athens, Greece.
}

Published by Sciedu Press 
ical resistance to infections. As a consequence, encephalitis occurs more frequently in elderly population than in young healthy groups and, at the same time, it leads to a more severe outcome from a clinical point of view and it should be more carefully approached. ${ }^{[1]}$ Several grounds may raise serious obstacles to medical personnel while diagnosing encephalitis. Among these, brain disorders such as dementia or brain stroke can cause important delays in diagnosis. More so, many co-morbid conditions which affect elderly population can have a negative impact on the course and efficiency of treatment and may cause secondary problems, such as acute hypercapnic respiratory failure (AHRF). If left untreated, AHRF may become life-threatening resulting in respiratory arrest, seizures, coma, and death.

In this case report, we highlight the difficulty of differentiated diagnosis and review investigations and management of meningoencephalitis in the case of elderly patients who develop AHRF.

\section{Case presentation}

Two patients, 72- and 75-year-old women, without prior respiratory problems, were admitted to our hospital during spring for shortness of breath, confusion and fever. During previous week before admission, patients manifested symptoms of influenza. They were examined by their primary care physicians and diagnosed with a viral illness. Although they received symptomatic measures, their clinical situation did not improve and thus, they were transported to the hospital. More so, their families noted nausea, sleepiness and stiff neck before admission.

Once arrived in the emergency room, on physical examination, patients had a fever of $38.7^{\circ} \mathrm{C}$ (patient 1) and $38.9^{\circ} \mathrm{C}$ (patient 2) respectively, heart rate of 96 (patient 1) and 99 (patient 2) as well as hypoxemia on room air. Lung examination was significant for diffuse bilateral rhonchi. Although patients were confused and uncooperative, neurologic examination was without tremor, asterixis, or obvious focal motor deficits, and deep tendon reflexes were intact.

Laboratory studies showed a white blood cell (WBC) count of $14,300 / \mu \mathrm{l}$ (patient 1 ) and $15,100 / \mu \mathrm{l}$ (patient 2) and a differential showing $78 \%$ (patient 1) and $80 \%$ (patient 2) neutrophils. Urine toxicology screen for benzodiazepines and microbes were negative. Chest radiograph was unremarkable. Liver function tests, including prothrombin time and serum albumin level, were within normal limits.

Patients were transferred to the ward and were treated with conservative measures. However, they rapidly developed hypercapnic respiratory failure. Consequently, both patients were intubated, mechanical ventilation was initiated and they were immediately admitted to the ICU. Their ABGs upon admission was notable for $\mathrm{pH} 7.12, \mathrm{PaCO}_{2} 70 \mathrm{mmHg}$, and $\mathrm{PaO}_{2} 40 \mathrm{mmHg}$ (patient 1) and $\mathrm{pH} 7.14, \mathrm{PaCO}_{2} 75 \mathrm{mmHg}$, and $\mathrm{PaO}_{2} 35 \mathrm{mmHg}$ (patient 2).

Repeated arterial blood gas sampling after initiation of mechanical ventilation, showed a normalized $\mathrm{pH}, \mathrm{PaO}_{2}$, and $\mathrm{PaCO}_{2}$. After normalization of ABGs, a weaning process followed. Weaning was unsuccessful as unexpected neurological semiotics were revealed (reduced level of communication, focal and generalized spasms).

Neurologists suggested neuroimaging through MRI of the brain. Results were unremarkable, revealing only microangiopathy.

However, non-immediate improvement of patients' classical image, aroused serious suspicions and we decided to carry out further tests. Thus, lumbar puncture with Cerebrospinal fluid (CSF) testing was immediately performed. CSF analysis was significant for $385 \mathrm{WBC} / \mathrm{ml}$ with $86 \%$ lymphocytes, protein $120 \mathrm{mg} / \mathrm{dl}$ (patient 1) and $397 \mathrm{WBC} / \mathrm{ml}$ with $92.6 \%$ lymphocytes, protein $122 \mathrm{mg} / \mathrm{dl}$ (patient 2) and revealed meningoencephalitis. No organisms were seen on Gram stain or culture. PCR for the detection of deoxyribonucleic acid (DNA) and ribonucleic acid (RNA) viruses in the CSF was performed. Once results were available, HSV-2 (patient 1) and CMV (patient 2) DNA were present in the CSF.

The attendant problems have been addressed accordingly, following specific guidelines. In this respect, patients were commenced on acyclovir intravenously, using a dosage of 10 to $15 \mathrm{mg} / \mathrm{kg}$ IBW IV every 8 hours for 15 (patient 1 ) and 21 (patient 2) days. Gradually, patients recovered and were released from the ICU to the ward after 42 (patient 1) and 7 days (patient 2).

\section{Discussion}

Early meningitis symptoms may mimic influenza. Symptoms may develop over several hours or over a few days. Viral infections are the most common cause of meningitis, followed by bacterial infections and, rarely, fungal infections. Meningoenephalitis may result in important rates of morbidity and mortality worldwide and especially in the case of elderly and other high-risk groups. Especially during influenza endemic periods, medical personnel who is consulted or directly cares for patients with symptoms of hypercapnic respiratory failure, must be able to discriminate it from many conditions that mimic it. ${ }^{[2]}$

Meningoencephalitis without other neuromuscular deficits caused by HSV-2 or CMV infection with hypercapnia has rarely been described. ${ }^{[3]}$ However, in the appropriate setting, 
critical care medical personnel should be aware of the event of viral meningoencephalitis in elderly patients with AHRF. This is so because, patients who died in the middle of influenza endemic period might well be classified, without any further investigation, as a death caused by flu. ${ }^{[4]}$ This is also the case especially for the management of elderly patients which, if inappropriate, may cause serious delays for the proper treatment of disease.

Given the range of conditions that cause AHRF, obtaining a thorough history is crucial. Important historical points include the presence of recent illness, ill contacts, unusual exposures (e.g. occupational, vector, and animal), outdoor activities, and ingestions.

Laboratory screening of blood, urine, as well as other body fluids can help detect and identify brain infection. Results from these tests can help exclude other diseases that mimic meningoencephalitis.

Concerning the neuroimaging techniques, MRI is preferred to CT given the increased sensitivity and specificity for evaluation of encephalitis. ${ }^{[5-8]}$ Chest imaging should also be performed, as focal infiltrates may be suggestive of certain pathogens (e.g., fungal or mycobacterial infections).

Our experience reveals that in cases of patients hospitalized in the ICU due to AHRF and who do not exhibit neurological abnormalities from the onset of illness, medical personnel should keep a high suspicion, as soon as they notice a change in their neurological picture. So, they should proceed with lumbar puncture and check of CSF as a routine examination in order have an accurate diagnosis of meningoencephalitis and to identify its etiologic agents. ${ }^{[9-13]}$ Then, the attendant problems of the disease should be treated accordingly, following specific guidelines. Eventually, especially in the case of elderly and other high-risk groups, prophylactic vaccination may be of crucial importance for preventing complications in patients who develop meningoencephalitis. However, once infected with meningoencephalitits, positive outcome of the disease depends on the immediate diagnosis and proper treatment of patients in the ICU.

\section{CONFLicts OF INTEREST Disclosure}

The authors have no competing interests to declare.

\section{REFERENCES}

[1] Öztürk S, Ege F. "Encephalitis in Elderly Population" in Hayasaka D (ed) Pathogenesis of Encephalitis. 2011: 47-60. PMid:21174597 https://doi.org/10.5772/20430

[2] Venkatesan A, Geocadin RG. Diagnosis and management of acute encephalitis: A practical approach. Neurology: Clinical Practice. 2014; 4(3): 206-15. https://doi.org/10.1212/cpj.00000000 00000036

[3] Harrison NA, MacDonald BK, Scott G, et al. Atypical herpes type 2 encephalitis associated with normal MRI imaging. Neurol Neurosurg Psychiatry. 2003; 74: 974-6. https://doi.org/10.1136/jnnp .74 .7 .974

[4] Foley PB. Encephalitis lethargica and the influenza virus. III. The influenza pandemic of 1918/19 and encephalitis lethargica: neuropathology and discussion. J Neural Transm. 2009; 116(10): 130921. PMid:19707847 https://doi.org/10.1007/s00702-009 $-0296-8$

[5] Steiner I, Budka H, Chaudhuri A, et al. Viral encephalitis: a review of diagnostic methods and guidelines for management. Eur J Neurol. 2005; 12: 331-43. PMid:15804262 https://doi.org/10.1111/ j.1468-1331.2005.01126.x

[6] Caprettia MG, Lanarib M, Tanic G, et al. Role of cerebral ultrasound and magnetic resonance imaging in newborns with congenital cytomegalovirus infection. Brain and Development. 2014; 36(3): 203-11. PMid:23647916 https ://doi .org/10.1016/j . braind ev.2013.04.001
[7] Marchbank ND, Howlett DC, Sallomi DF, et al. Magnetic resonance imaging is preferred in diagnosing suspected cerebral infections. BMJ. 2000; 320: 187-8. PMid:10634753 https://doi .org/10.1 $136 / \mathrm{bmj} .320 .7228 .187$

[8] Chaudhuri A, Kennedy PGE. Diagnosis and treatment of viral encephalitis. Postgrad Med J. 2002; 78: 575-83. PMid:12415078 https://doi.org/10.1136/pmj.78.924.575

[9] Sempere AP, Berenguer-Ruiz L, Lezcano-Rodas M, et al. Lumbar puncture: its indications, contraindications, complications and technique. Rev Neurol. 2007; 45(7): 433-6. PMid:17918111

[10] Granerod J, Ambrose HE, Davies NW, et al. Causes of encephalitis and differences in their clinical presentations in England: a multicentre, population-based prospective study. Lancet Infect Dis. 2010; 10: 835-44. https://doi.org/10.1016/S1473-3099(10) 702 $22-\mathrm{X}$

[11] Glaser CA, Honarmand S, Anderson LJ, et al. Beyond viruses: clinical profiles and etiologies associated with encephalitis. Clin Infect Dis. 2006; 43: 1565-77. PMid:17109290 https ://doi .org/10.1 $086 / 509330$

[12] Mailles A, Stahl JP. Infectious encephalitis in France in 2007: a national prospective study. Clin Infect Dis. 2009; 49: 1838-47. PMid:19929384 https://doi.org/10.1086/648419

[13] Rafailidis PI, Kapaskelis A, Falagas ME. Cytomegalovirus meningitis in an immunocompetent patient. Med Sci Monit. 2007; 13(9): CS107-9. PMid:17767122 